\section{CAPITALISMO E ANGÚSTIA}

\section{Capitalism and Anguish}

\author{
Capitalismo y Angustia
}

Capitalisme et Angoisse
Biopolítica e Subjetividades
Contemporâneas

\title{
Resumo
}

Este trabalho apresenta uma reflexão sobre possíveis relações que se estabelecem entre a angústia e os impactos da normatividade social sobre as subjetividades. Em nossos dias, o capitalismo, aliado à ciência moderna, caracteriza-se não só pela definição autoritária de políticas econômicas, mas também por mecanismos gestionais que regulam e afetam a constituição dos indivíduos, estimulando a emergência de diferentes formas de manifestação da angústia, tais como estresse, pânico, desamparo, traumatismo e depressão, que se caracterizam particularmente pelo silencio do sujeito frente ao sentimento de perda de horizontes estáveis de referência, ou seja, pelo sofrimento sem endereço, sem Outro. Recorremos à psicanálise e a algumas ideias de Giorgio Agamben sobre o capitalismo de hoje para discutirmos essas questões, assim como sobre as possibilidades de a psicanálise e a arte serem consideradas modos particulares de confronto com esses fatos civilizatórios que exacerbam a angústia, colocando-se, portanto, na contramão dos interesses capitalistas.

Palavras-chave: psicanálise; arte; capitalismo; angústia.

\section{Abstract}

This paper presents a reflection on possible relationships established between anxiety and the impact of social norms on subjectivities. Nowadays, capitalism, combined with modern science is characterized not only by the authoritative definition of economic policies, but also by gestionais mechanisms that regulate and affect the constitution of individuals, encouraging the emergence of different forms of distress manifestation, such as stress, panic, helplessness, trauma and depression, which are particularly characterized by the silence of the subject facing the feeling of loss of stable horizons of reference, i.e., by suffering with no address, no Another. We resort to psychoanalysis and some Giorgio Agamben's ideas about the capitalism today to discuss these issues, as well as the possibilities of psychoanalysis and art to consider specific ways of confronting these civilizational facts that exacerbate the anxiety - placing itself against the capitalist interests.

Keywords: psychoanalysis; art; capitalism; anguish.

\section{Resumen}

Este trabajo presenta una reflexión acerca de posibles relaciones que se establecen entre la angustia y los impactos de la normatividad social sobre las subjetividades. En nuestros dias, el capitalismo, aliado a la ciencia moderna, se caracteriza no solo por la definición autoritaria de politicas económicas, pero también por mecanismos de gestión que regulan e influyen en la constitución de los individuos, estimulando la emergencia de distintas

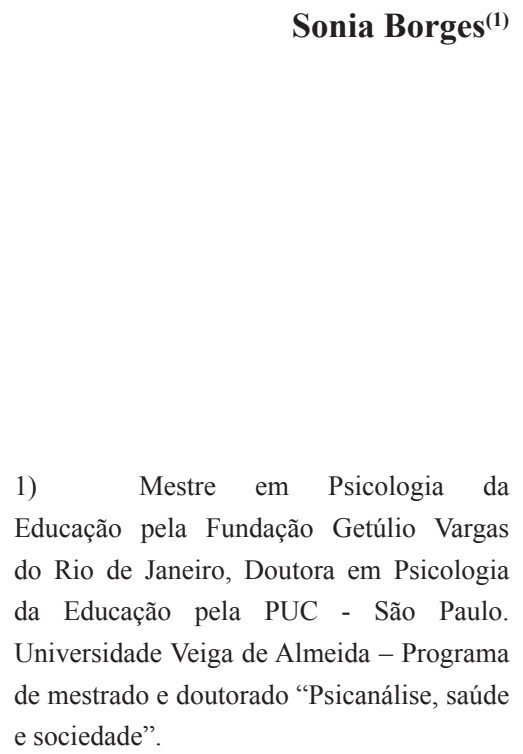

e sociedade". 
formas de manifestación de la angustia, tales como estrés, pánico, desamparo, traumatismo y depresión, las cuales se caracterizan por el silencio del sujeto ante el sentimiento de pérdida de horizontes estables de referencia, es decir, por el sufrimiento sin ubicación, sin otro. Recurrimos a la psicoanálisis y a algunas ideas de Giorgio Agamben acerca del capitalismo de hoy para discutirnos estas cuestiones, asi como las posibilidades de la psicoanálisis y el arte sean consideradas particulares modos de confronto con estos hechos civilizatorios que aumentan la angustia-poniéndose, por lo tanto, a la contraria de los intereses capitalistas.

Palabras clave: psicoanálisis; arte; capitalismo; angustia.

\section{Résumé}

Cet article présente une réflexion sur des relations possibles qui s'établissent entre l'angoisse et les impacts dans la normativité sociale sur les subjectivités. Aujourdh'ui, le capitalisme, lié à la science moderne, se caractérise non seulement par la définition autoritaire des politiques économiques, mais aussi par les mécanismes gestionnaires qui règlent et touchent la constitution de individus, en stimulant l'urgence de différentes manières de manifestation d'angoisse : stress, panique, abandon, traumatisme et dépression, lesquelles se caractérisent par le silence du sujet face au sentiment de perte des horizons stables de référence, c'est à-dire, par la souffrance sans adresse, sans l'Autre. On prend des références de la psychanalyse et de quelques idées de Giorgio Agamben à propos du capitalisme d'aujourd'hui à fin de discuter cettes questions et aussi les possibilités de la psychanalyse et de l'art être considérées comme moyan particulier de confronter ces faits civilisatoires qui exaspèrent l'angoisse - restant, donc, en face des intérêts capitalistes.

Mots-clés: psychanalyse; art; capitalisme; angoisse.

$\mathrm{Na}$ clínica psicanalítica, encontramos muitas vezes manifestações de angústia devastadoras que podem explodir os referenciais que sustentam o eu, inclusive as possibilidades do sujeito de se identificar, fantasiar e exercer as suas capacidades criativas. Com Freud (1926/2006a), aprendemos que a angústia é estrutural. Todos nos deparamos com o impasse irredutível da angústia de castração. Lacan desenvolve essas ideias ao trabalhar o tema da angústia, relacionando-a com a posição que o sujeito assume frente à demanda do Outro. Estar aprisionado, alienado ao desejo do Outro, afirma Lacan, impede a própria emergência do sujeito enquanto tal. "Sujeito é desejo", repete diversas vezes ao longo de $O$ Seminário, livro 6: $O$ desejo e sua interpretação (1959-1960), remetendo-nos à falta que nos é constitutiva na sua relação com a demanda do Outro. Também na primeira lição de O Seminário, livro
10: A angústia (1962-1963/2005), Lacan marca a relação essencial da angústia com o desejo: todo sujeito, diante do enigma do desejo do Outro - "o que o Outro quer de mim?" -, é tomado de angústia. Esse é um momento paradoxal de desamparo, angústia pelo desamparo, em que cada um se interroga sobre o que é, ou sobre o que representa para o Outro enquanto universo simbólico, ou discursivo, no qual está inserido.

Mas Lacan se pergunta: “o que é a angústia?” e, com Freud, afirma que é um afeto. E, por ser afeto, não é recalcado: "Ele se desprende, fica a deriva. Podemos encontrá-lo deslocado, enlouquecido, invertido, metabolizado, mas ele não é recalcado. O que está recalcado são os significantes que o amarram" (Lacan, 1962-1963/2005, p. 22). Mais adiante, conceitua de maneira mais clara a angústia como "um afeto que não engana", destacando o seu aspecto de sinal, sinal no eu que é um chamado a se remediar o desamparo, já que este está na base do afeto da angústia. A angústia emerge de forma concomitante com o desamparo próprio à experiência do sujeito de não conseguir dar nome à causa de seu sofrimento, ou expressar seu desejo - vivências no eu que expressam o seu aniquilamento e a consequente afânise do sujeito diante de um Outro ameaçador.

Nesse sentido, Lacan (2005) realça que é possível "amarrar" modalidades da angústia às diversas formas de laço social, isto é, que é possível constatar que a natureza desta forma de sofrimento psíquico, a angústia, está vinculada aos impactos dos dispositivos de normatividade social sobre a constituição dos indivíduos. Referia-se, assim, aos efeitos próprios das relações entre o capitalismo e a ciência moderna que hoje produzem formas de angústia caracterizadas pelo sentimento de perda de horizontes de referência, pelo sofrimento sem endereço, sem Outro, que retrata bem a afânise do sujeito na atual conjuntura em que a angústia é registrada com palavras novas: estresse, pânico, traumatismo, pressão ou depressão. Mal-estar que evidencia os efeitos da homogeneização, da prisão aos clichês que agenciam a impossibilidade de narrar e de nomear, de se dizer como sujeito desejante, exilado que se está de sua subjetividade.

No presente trabalho, visamos discutir estas ideias, a partir de concepções de Lacan, particularmente presentes em O Seminário, livro 10: A angústia (1962-1963/2005). Introduziremos também algumas ideias de Giorgio Agamben que, ao explicitarem as características do capitalismo hoje, corroboram com a perspectiva lacaniana de que em nossos tempos os laços sociais são particularmente propiciadores de angústia.

\section{Amarrações da Angústia}

Lacan usa a expressão "amarração da angústia às diferentes conjunturas" (Lacan, 1962-1963/2005, pp. 32- 
33) para referir-se às mutações da angústia como efeito do que Freud chamou de "civilização", e que Lacan passou a chamar, a partir de $O$ seminário, livro 17: $O$ avesso da psicanálise (1969-1970/1992b), de ordem discursiva. Contudo, Lacan observa que a "matriz" dessas mutações é sempre a mesma: "a angústia emerge quando algo aparece no imaginário, ali onde nada deveria aparecer" (Lacan, 1962-1963/2005, p. 53). Mas também insiste em que há conjunturas sócio-políticas que favorecem a emergência da angústia. Cita como exemplo, além das grandes catástrofes e os males advindos das doenças, as destituições subjetivas provocadas pelas exigências atuais do capitalismo tardio. Neste último caso, a proeminência dos interesses do mercado tem em comum com os primeiros, trazer o sentimento, que se alastra sobre os sujeitos, de não se sentirem capazes de se esquivar de algo que os invade de modo insuportável, algo impossível de ser simbolizado.

Colette Soler (2012) propõe que, para se apreender o que Lacan chamou de "amarrações da angústia às diversas conjunturas", evidenciando que as características desse afeto podem variar conforme as mutações sociais, é preciso examiná-las levando em consideração as relações entre a (pequeno outro), A (grande Outro) e $a$ (objeto a), que estão aí implicadas, já que, em qualquer situação, o desejo está em causa. Antes mesmo de estar amarrado ao objeto $a$, causa de desejo, o desejo o está á demanda do Outro. A angústia está sob o eixo da relação $\$$ e A, ou seja, está no encontro entre estas duas incógnitas.

"O que o Outro quer de mim?", pergunta o sujeito. No entanto, sob angústia, esse desejo que é sempre do Outro, pode nem mesmo fazer enigma, a partir do qual se poderia responder a essa questão pela formulação de um desejo. Para ilustrar esta posição subjetiva, Lacan conta que:

Um homem, dotado de uma máscara, encontra-se diante de um louva-deus que lhe parece gigante. A máscara de louva-deus pode levar o inseto a tomá-lo, não somente como objeto sexual, mas de gozo, posto que, como se sabe, a fêmea do louva-deus mata seu parceiro após o ato. (Lacan, 1962-1963/2005, p. 32)

Podemos pensar que o louva-deus está no lugar do A (grande Outro) e, pela via desse confronto, só poderia restar ao sujeito a posição de objeto a ser devorado. Lacan também se refere ao pesadelo para evidenciar esta dimensão em que o gozo do Outro é dominante. "A angústia do pesadelo é experimentada como aquela do gozo do Outro" (Lacan, 1962-1963/2005, p. 73), afirma, e o ilustra com o mito dos demônios masculino e feminino, o íncubo e o súcubo, que vêm abusar do sujeito durante o sono, colocando todo o seu peso sobre o seu peito, esmagando-o com seu gozo de tal forma que os mecanismos do sonho, determinados pelo desejo, congelam-se em um impasse de angústia contra o qual só resta ao sujeito despertar. O pesadelo não ocupa o mesmo lugar que o sonho. Não é realização de desejo, não tem nada a ser decifrado, não há texto, há o horror, há irrupção de algo heterogêneo ao significante. Ou seja, o pesadelo indica um sujeito na posição de objeto do gozo do Outro.

O desejo é do Outro, a alienação é da ordem do necessário, mas o desejo é do sujeito a partir de sua separação da demanda do Outro. Que paralelo poderíamos fazer entre esta fábula e a questão da angústia, na sua relação com o desejo na atual conjuntura? Conjuntura que seria particularmente propícia a seu desenvolvimento em decorrência dos atuais modos de gozo, relativos à conjugação do discurso capitalista com o da ciência moderna?

A filosofia sempre insistiu sobre o tema da angústia. Pascal, Kierkegaard, Heidegger e Sartre o abordaram, deixando marcas na história do pensamento. Kant, em sua antropologia, define a angústia como um afeto que escapa ao discernimento. Define os afetos conforme "graus" de temor: fala da ansiedade, da angústia, do pavor, do horrorizar-se, entre outros. Kierkegaard já tem outro modo de conceber a angústia. Para ele este conceito está relacionado com o pecado. E o pecado, por sua vez, como motivo para inquietações angustiantes. Mas foi com o aparecimento da obra Ser e tempo (1927/2002), de Heidegger, que uma nova luz foi lançada sobre o estudo deste tema, trazendo mudanças não só para a filosofia, mas todas as disciplinas que se debruçam sobre o estudo do psíquico. Heidegger não concorda com Kant nem com Kierkegaard, para os quais a angústia teria um caráter contingente. Para ele, esse afeto é constituinte, fundamental do ser, do existir humano, no sentido de que ela abre este ser para a sua propriedade.

Lacan, remetendo-se e mesmo subvertendo o pensamento destes filósofos, ressalta que, em nossos tempos, "os espaços infinitos empalideceram por trás das letrinhas" (Lacan, 1961/1998b, p. 690). Referia-se, assim, aos efeitos da invasão da ciência moderna, conjugada aos interesses do capitalismo, em todos os domínios da vida humana, provocando o que definiu como um "clamor generalizado". Lacan amava observar que, depois de constituídas em fórmulas ou algoritmos, nada poderia deter as pequenas letras da ciência, apontando, com isto, a mutação que se opera entre o discurso científico (de Descartes, Galileu e Newton) e o discurso da ciência, que deve ser entendido como uma nova forma de laço social. Nova forma de laço social porque fundado na crença de uma possível reificação do sujeito, já que colocado no lugar de objeto subsumido pelos interesses do mercado.

O "clamor generalizado", na expressão de Lacan, que hoje constatamos, é explicado por Soler (2012) como sendo, na atual conjuntura, voz do sofrimento sem endereço, sem Outro, que é bem retratado pelas novas características de que a angústia se reveste hoje, sendo a angústia e o desamparo definidos como estresse, pânico, traumatismo, pressão ou depressão. As próprias sociedades contemporâneas 
se apresentam como corpos inertes atravessados por gigantescos processos de destituição subjetiva.

Entretanto, neste mundo aparentemente ordenado, tendo em vista a sua perpétua reprodução, a angústia surge. Surge quando algo do real apaga - e sempre apaga - essa aparência de perfeita ordem, instante este em que emerge justamente a ameaça de se realizar a abolição da perda primordial e da função de causa do desejo. A angústia surge quando, diante da face do Outro, produz-se o silêncio, amordaça-se a criatura. E o que acontece?

Como acontecimento real, esse silêncio transborda no imaginário, tendo como efeito a queda selvagem das identificações e fantasias, sustentáculos do eu. Aprendemos com Freud que a angústia é experimentada no eu, podendo ter como efeito arrebentar os seus quadros assegurados normalmente pela fantasia. Neste caso, nos momentos de emergência da angústia, o vivente se experimenta em sua não autonomia de sujeito, como assinala Lacan (19591960), mas como puro objeto, como no exemplo do louvadeus e de toda literatura fantasmática. Nesta, os vampiros, tão presentes nesta literatura, têm, inicialmente, uma imagem de bonzinhos, familiares. Porém, quando começam a aparecer seus "dentinhos", o que faz com desapareça sua imagem de pessoas comuns, surgindo o "estranho" com as suas intenções. Intenções de quem só quer "isso", figurado pelo corpo do sujeito a ser chupado, dessangrado. São figuração do sujeito que experimenta o desamparo derivado de sua posição de objeto do gozo do Outro.

Isso explica porque, em suas análises, os sujeitos podem manifestar o sentimento de estarem sendo teleguiados. Não quer dizer que o sujeito seja um psicótico, não se trata de uma estrutura delirante, mas da sensação angustiante de que algo o impele a fazer determinada coisa, sensação que pode ser vivida como compulsão a atender ao chamado mudo do Outro. Drácula não fala. O flautista de Hamelin também nos ensina sobre isto. O horror que este conto produz se relaciona ao poder que pode adquirir o desejo de alguém sobre nós. $\mathrm{O}$ estranho é que o flautista não diz nada, mas sua música opera como se dissesse. Lacan, trabalhando o tema, afirma:

Neste ponto, HEIM se revela [...] como desejo do Outro, aqui o desejo no Outro, poder-se-ia dizer que meu desejo entra no Outro, onde era esperado desde toda a eternidade, sob a forma do objeto que sou na medida em que me exila de minha subjetividade! (Lacan, 1962-1963/2005, pp. 5859).

Lacan, justamente por se tratar de uma vivência no eu, recorre ao espelho para deixar mais clara esta relação entre a emergência da angústia evidenciada em um fracasso imaginário e simbólico da manutenção da condição subjetiva nesta relação. Lacan afirma que na situação de desamparo, o sujeito se encontra sem recursos. Mas sem recursos em que sentido? Exilado de sua subjetividade, o Outro pode "literalmente aspirá-lo". Neste sentido, fica esclarecida a função do objeto a, ela está ligada à relação pela qual o sujeito se constitui em relação ao seu lugar do Outro, o grande A, que é o lugar onde se ordena a realidade significante. É no ponto em que todo significante falha, se abole, no ponto nodal dito do desejo do Outro, no ponto dito fálico - pelo que ele significa a abolição como tal de toda significância - que o objeto pequeno a vem tomar seu lugar, não de objeto de desejo, mas de angústia.

Como ensina Lacan (1962-1963/2005), trata-se aí de uma opacidade que promove a impossibilidade de se buscar qualquer recurso subjetivo. A angústia e o desamparo são constitutivos do sujeito. Mas, como vimos defendendo, em decorrência de suas amarrações a determinadas conjunturas, as referências imaginárias do eu acabam por oscilar. Nesses momentos, frente às demandas contraditórias ou opacas do Outro, marcadas hoje, inclusive, pela ruptura dos ideais humanitários, a angústia surge como função mediadora entre a condição de objeto, dejeto, em relação a um Outro não barrado resistente à significação.

Quando isto ocorre, o sujeito fica à mercê do Outro, como tão bem exemplificam essas situações de confronto com o estranho. Percebe-se como objeto do Outro, sendo a angústia a tradução subjetiva disto. Não a angústia primordial, mas a que rompe as barreiras protetoras do sujeito diante dos estímulos, modificando a relação habitual que se estabelece entre angústia e objeto, restando-lhe sintomatizar.

Assim como Freud em "O mal-estar na cultura" (1930/2006b), Lacan (1969-1970/1992b) preocupa-se com o mal-estar na modernidade, diagnosticando-o, em última instância, como produto do discurso capitalista. Como discurso que rege hoje os laços sociais, na sua conjugação com o discurso da ciência, o capitalismo tem como característica a destruição de crenças e objetivos, ou seja, os laços sociais neles fundados, por sobrepor o mercado, cujas leis são reguladas por uma mão invisível, portanto sem regulação possível. Na verdade não há leis, há imperativos. O discurso do capitalista, diz Lacan, fabrica um sujeito do desejo, do desejo de ser rico. Sua marca é a recusa da castração, que exclui o outro do laço social em seu apelo para que o sujeito se relacione com os objetos-mercadorias, comandado pelo significante-mestre, o capital. Dessa condição resulta o que Giorgio Agamben definiu como a "vida nua", a do homem reduzido à sua biologia.

\section{A "Vida Nua"}

A partir dessas considerações de Lacan, consideramos pertinente trazer para este trabalho, ainda que brevemente, as concepções de Giorgio Agamben sobre o capitalismo em nosso tempo. Recorreremos particularmente às suas 
concepções sobre o que chamou de "vida nua", "Voz", "dispositivo" e "profanação". Agamben é jurista e filósofo, além de um dos pensadores mais lidos da atualidade. Sua obra tem início nos anos 1970, com ênfase no debate em torno da estética e da obra de arte. A partir dos anos 1990, torna-se lugar de contundentes reflexões políticas que, embora inspiradas ou mesmo fundamentadas em Foucault e Hanna Arendt, são desenvolvidas com grande originalidade.

Para Agamben (2002, p. 16), "o que está em questão, é a "vida nua" do cidadão, o novo corpo biopolítico da humanidade", concepção que traz, em si mesma, as críticas aos efeitos do capitalismo sobre os sujeitos. A "vida nua", para o filósofo, é resultante de articulações da política e do direito no exercício do poder soberano em constante estado de exceção, que separa os indivíduos de seu contexto societário, produzindo vidas destituídas de Voz, de linguagem e de cultura. Vidas reduzidas à pura biologicidade e, sob tais condições podendo ser submetidas a situações limites de vida e de morte de acordo com os interesses e a lógica do poder em curso.

Como veremos adiante, a concepção de "vida nua", assim como de "dispositivo" e "profanação" são definidos pelo filósofo no contexto de seu pensamento sobre as particularidades de que se revestem, hoje, as relações de poder: a centralidade da economia e da racionalidade administrativa, cuja lógica destitui os sujeitos de sua Voz, ou seja, do seu lugar de sujeitos de sua história. Em comum com a psicanálise, Agamben valoriza a linguagem, a fala, menciona a Voz, a que atribui lugar central nos processos emancipatório da posição de subjugação aos ideais propugnados pelo discurso capitalista.

Alinhado a essas ideias sobre o capitalismo contemporâneo, o filósofo Slavoj Žižek, inspirado na leitura das elaborações de Lacan sobre os discursos que regem os laços sociais, aponta para o fato de que o capitalismo interpela os sujeitos como consumidores, solicitando neles sempre desejos novos, perversos e excessivos - para os quais oferece produtos que supostamente os satisfariam. Há "uma manipulação do desejo de desejar, celebrando-se este sempre com novos modos e objetos de prazer" (Žizek, 1992).

Para Agamben (2002), o capitalismo generaliza e absolutiza os princípios que regem o capitalismo como reverenciáveis por si mesmos, sagrados e veneráveis. Em todos os âmbitos da vida humana, tudo que é feito, produzido ou vivido - também o corpo humano, a sexualidade, a própria linguagem - é colocado no âmbito do consumo.

Em $O$ que é o contemporâneo? (Agamben, 2009), o filósofo faz uma descrição destas formas modernas do capitalismo recorrendo ao significante "dispositivo". A sua inspiração para o desenvolvimento desse conceito é o termo positivitè, já usado por Foucault para descrever estratégias políticas do poder. Entretanto, o próprio Foucault, conforme longa pesquisa desenvolvida por Agamben, já trouxe esse termo de Hippolite que, por sua vez, faz uso do termo inspirado em Hegel, em quem a "positividade" é relativa à coerção, ao obstáculo à liberdade humana. Em Agamben, "dispositivo" tem seu sentido inspirado na história desta noção , mas adquire um sentido bastante próprio: o dispositivo é "qualquer coisa que tenha, de algum modo, a capacidade de capturar, orientar, determinar, interceptar, modelar, controlar, assegurar os gestos, condutas, as opiniões e os discursos dos seres viventes" (Agamben, 2009, p. 14). Em O que é um dispositivo? (2014), o filósofo resume em três pontos o seu pensamento sobre este termo:

1) É um conjunto heterogêneo, que inclui virtualmente qualquer coisa, linguístico e não linguístico no mesmo título: discursos, instituições, edifícios, leis, medidas de segurança. Proposições filosóficas, etc. O dispositivo em si mesmo é a rede que se estabelece entre estes elementos.

2) O dispositivo tem sempre uma função estratégica concreta e se inscreve sempre numa relação de poder.

3) Como tal resulta do cruzamento de poder e relações de poder. (Agamben, 2014, p. 25)

filósofo:

Ainda esclarecendo o que são dispositivos, diz o

Aquilo que procuro individualizar com este nome é, antes de tudo, um conjunto absolutamente heterogêneo que implica discursos, instituições, estruturas arquitetônicas, decisões regulamentares, leis, medidas administrativas, enunciados científicos, proposições filosóficas, morais e filantrópicas. Em resumo: tanto o dito como o não-dito, eis os elementos dos dispositivos. O dispositivo é a rede que se estabelece entre estes elementos. [...] Disse que o dispositivo tem natureza essencialmente estratégica, que se trata, como consequência, de uma certa manipulação de força, de uma intervenção racional e combinada de relações de força, seja para orientá-las numa determinada direção, seja para bloqueá-las, ou para fixá-las e utilizálas. O dispositivo está sempre inscrito num jogo de poder e, ao mesmo tempo, sempre ligado aos limites do saber, que derivam deste ao mesmo tempo que o condicionam. Assim, o dispositivo é um conjunto de estratégias de relações de força que condicionam certos tipos de saber e por ele são condicionados. (Agamben, 2009, pp. 299-300)

Os dispositivos contemporâneos funcionam como "máquinas de governo". Diferentes dos ditos tradicionais (as escolas, prisões, a confissão), os dispositivos de hoje (a internet, os telefones celulares, a televisão, as câmeras de monitoramento urbano etc.) não nos permitem mais constatar a produção de um sujeito dito real, mas uma recíproca indiferenciação entre subjetivação e dessubjetivação que não dá lugar à composição ou à recomposição de um sujeito. 
"Na não-verdade do sujeito não há mais, de modo algum, a sua verdade" (Agamben, 2009, p. 40).

Conforme esse autor, quanto menos subjetividades são formadas no corpo a corpo dos indivíduos com os dispositivos, mais dispositivos são criados como tentativa inelutável de sujeição destes. Agamben ainda afirma:

A categoria da subjetividade no nosso tempo vacila e perde a consistência: trata-se, para ser preciso, não de um cancelamento ou de uma superação, mas de uma disseminação que leva ao extremo o aspecto de mascaramento que sempre acompanhou toda identidade pessoal. (Agamben, 2009, pp. 41-42)

"Desta indiferenciação não resta senão um sujeito espectral" (Sramin citado por Agamben, 2009, p. 14). Diante do afirmado, parece-nos possível aceitar a hipótese de que os mecanismos gestionais produtivos marcam toda a ação humana no presente cenário: é a barra sobre o sujeito que é visada, para ser eliminada, como se o desejo humano pudesse ser suturado definitivamente pelos "dispositivos". Trata-se aí do discurso do mestre, mas não do mestre antigo, que não era tão angustiante como o do contemporâneo, já que mais facilmente conseguia obturar as fontes de angústia. Lacan, em O Seminário, livro 3: As psicoses (1955-1956/1992a), expressa bem isso quando comenta a habilidade da Igreja e dos padres que, naqueles tempos, conseguiam realizar a proeza de transformar o proclamado e desejável "temor a Deus", num misto de amor com pavor.

Agamben divide o existente em duas categorias: os viventes e os dispositivos. O termo "dispositivo", como se viu, nomeia aquilo que e por meio do qual se realiza uma pura atividade de governo, sem nenhum fundamento no ser. Por isso mesmo, implica um processo de subjetivação, isto é, deveria produzir seu sujeito. Mas que sujeito? Supostamente, hoje, tudo deveria se passar como se o sujeito pudesse, com seus objetos, engendrados nesse processo, dar corpo ao único objeto que, faltando estruturalmente, diz respeito ao seu desejo.

Para Lacan, como explicitou Žižek (1992), é próprio do capitalismo e da superabundância dos bens que engendra dessexualizar o desejo para reenviá-lo aos objetos de consumo valorizados socialmente. Mas nesse contexto, a sua erotização aparece como secundária. Tudo se passa, então, como se esses próprios objetos, objetos técnicos, próteses, substitutos do objeto do desejo, preparassem o sujeito para ser, ele mesmo, objeto na grande cena do mercado.

"Deus não morreu. Ele tornou-se dinheiro", afirma Agamben (2012) em entrevista concedida à Revista Ragusa News. O capitalismo, continua, é uma religião como jamais existiu, porque não conhece redenção, nem trégua. Ele celebra um culto ininterrupto, cuja liturgia é o trabalho e cujo objeto é o dinheiro (Agamben, 2012).

O capitalismo é uma religião puramente cultual, a mais cultual que já existiu. Mas nada nela tem relação imediata com o culto, não tem dogma nem teologia. É o utilitarismo que lhe dá a conotação religiosa. Segundo o Direito romano, as coisas sagradas ou religiosas eram coisas subtraídas da vida comum. O capitalismo, tal como as "outras religiões", promove essa subtração das coisas da esfera profana.

Nesse contexto, qual a resposta dos "senhores dos dispositivos"? As dificuldades sociais e individuais são concebidas como um "desfuncionamento" a ser corrigido por técnicas de resolução de problemas. Desconsidera-se a dimensão singular e enigmática do sujeito. Uma fobia, uma tristeza, a angústia, são reduzidas a um conteúdo irracional a ser suprimido, apagado para que se restabeleça o bom funcionamento da "Máquina Humana", termo também de Agamben.

Correntes atuais de pensamento sugerem o acolhimento dessa situação, tida como inevitável, frente a qual restaria apenas a busca de um melhor gerenciamento dos mecanismos políticos. Nesse sentido, o discurso capitalista estimula a multiplicação de objetos (gadgets) que supostamente eliminariam a angústia, por tamponar a falta constitutiva do sujeito - resto de seu desejo nunca também passível de tamponamento.

Agamben, no entanto, convida à outra estratégia. $O$ fato de a vida humana ter se transformado em objeto soberano dos dispositivos dita em outra saída, a saber, a "profanação dos dispositivos de governo e a assunção de um ingovernável como ponto de fuga e início de uma nova política" (Agamben, 2007, p. 14). Essa é a contribuição no debate sobre os efeitos do capitalismo. Consiste em mostrar como a "vida nua" vai progressivamente coincidindo com o que seria possibilidade hegemônica de vida que pode ter lugar no espaço político. Mas o que propiciaria este movimento profanatório?

Do ponto de vista psicanalítico, não estaria no sujeito desejante, no desejo indestrutível, a possibilidade de uma nova política? Considerando-se, inclusive, a angústia como sinal de haver ali um sujeito? Freud (1937/2006c) já nos avisava sobre a impossibilidade de governar. E a experiência clínica do inconsciente não cessa de revelar que é só ao preço do ato falho, do sonho, do sintoma e da angústia sinais de sujeito - que pode ocorrer a emergência do novo. Contrária à ideia de que o perfeito funcionamento da máquina social, ou a harmonia, conduziriam à saúde, para a psicanálise é preciso deixar lugar ao furo. A psicanálise nos permitiria entrever outro modo de confronto com os fatos da civilização? A psicanálise e a arte - aqui nos referimos particularmente à contemporânea - não teriam em comum a possibilidade de exercer esta "profanação"? Ou seja, desenvolver aquilo que poderia profanar a concepção do capitalismo como sagrado? Fazer outro uso das coisas, diz o filósofo, estabelecendo laços sociais em outras bases. "A profanação do improvável é a tarefa política da geração que vem", assevera Agamben (2009), sem hesitação. 


\section{Arte e Psicanálise como Dispositivos de Profanação}

Diferente da pretensão de aperfeiçoar as instituições humanas, numa perspectiva tecnicista, médica, que calam o sujeito, o olhar da psicanálise está sobre o furo que, sintomático, não pode ser tamponado no coração mesmo dos dispositivos que se quer aperfeiçoar. Por isso mesmo, considera que não se deve calar o sintoma nem mesmo a angústia, mas fazê-los falar, propiciando, desse modo, a emergência de sujeito. A psicanálise promete uma ética do bem dizer: o sujeito é convocado a sustentar uma palavra sobre o que causa seu desejo. A angústia não engana, ela é sem causa, mas não sem objeto, ensina Lacan (19621963/2005). Mas ela também permite ao sujeito reconhecer que o Outro que lhe transmite a linguagem não tem a última palavra que tamponará sua falta real.

O sintoma conta a história particular do sujeito, apontando para o seu desejo, sempre singular. Também sempre enigmático, mas que aponta para um sentido, o sentido perdido pelo sujeito que, no entanto, quando bem dito, o diz também na sua diferença. Para a psicanálise, é dever ético acolher o sintoma.

Ao contrário do discurso da ciência, que aborda o sintoma como "desfuncionamento", para a psicanálise, o sintoma é índice de uma verdade singular, subversiva, dissidente em relação às normas prescritas pelos discursos. Lugar de "profanação dos dispositivos", portanto. Os avanços de Lacan sobre esse tema levaram a considerar o sintoma como uma suplência a que os sujeitos falantes recorrem para dar sentido ao traumático encontro com o real do gozo.

Suas últimas formulações sobre o sintoma foram particularmente inspiradas na poética de James Joyce, ou, melhor dizendo, na prática original de Joyce com a letra que, para Lacan, "identificou-se com o individual, chegando ao ponto extremo de encarnar nele o sinthoma" (Lacan, 1975/1998a, p. 161).

Em comum, a psicanálise e a literatura, ou seja, as artes, também exerceriam a "profanação dos dispositivos", tal como pensados por Agamben. Picasso, à pergunta "de onde vem a obra de arte?", responde: "a criação plástica é apenas secundária. $\mathrm{O}$ que conta é o drama do próprio ato criativo, o momento em que o universo se evade para encontrar sua própria destruição" (Picasso citado por Pommier, 1990, p. 191). A arte moderna e a contemporânea, que nascem no século $\mathrm{XX}$, diferem da clássica, arte metafórica, contemplativa, que nas suas relações com o belo tem a função de velar a falta e o furo. A "nova arte", em lugar da contemplação, propõe a experiência. É conceitual, tem função crítica, política. "Experimentá-la" divide o sujeito, pelo que provoca de desconforto, angústia, porque é, estranhamente, um questionamento, não do objeto que supostamente evocaria, mas da própria relação de objeto, apontando para o furo no real. Como Gerard Wajcman (2008) comenta, essa arte pode ser considerada como o que, por sua pura presença de objeto, coloca-nos, ironicamente, frente a frente com a ausência. Faz-nos ver a falta essencial que habita e susta todo objeto: "objeto, então, celibatário, objeto casado com a ausência, que mostra profundamente o que é um objeto" (Wajcman citado por Depelsenaire, 2008, p. 31).

A queda do véu, que recobria a representação pictural destinada a ser contemplada, confronta o espectador contemporâneo com o objeto real, não mediatizado, de modo a serem modificadas as balizas tradicionais de ordenamento da arte: as relações forma/conteúdo, continente/conteúdo, visível/invisível. Trata-se, com a "nova arte", de presentificar o real e suscitar mal-estar e angústia. Está em questão também, assim como no campo da psicanálise, o furo, a falta constitutiva que causa angústia, mas que promove o desejo. Ao contrário do que pretende a ciência a serviço do capitalismo, que é tamponar essa falta com seus gadgets, trata-se, nesse caso, de realçá-la.

Neste sentido, a obra de Francis Bacon é exemplar. Bacon é aclamado como um dos maiores pintores de nosso tempo. Em suas entrevistas, afirma que, para ele, pintar teria como único objetivo a mencionada profanação dos "dispositivos" com seu poder de homogeneização. Atribuía à angústia, que comumente antecede o ato criativo - e da qual tantos artistas se queixam - ao fato de sempre ocorrer, neste momento, um confronto com os clichês. No seu caso, dizia ele, nunca se defrontava com uma tela em branco, mas povoada de clichês. Sua pintura é uma forte crítica à representação mimética, pela subversão que sua obra promove das relações forma/conteúdo, dentro/fora, sensível/inteligível, tão preciosas, por exemplo, ao mundo acadêmico que vive do objetivo de comprová-las em sua insistência de fazer existir o objeto do conhecimento. $\mathrm{Na}$ esteira de Bataille, para quem "o universo não se parece com nada, no máximo com uma aranha ou um cuspe" (Bataille, 2006 , p. 217), Bacon visa pintar, no lugar do objeto, o abjeto. O abjeto pode ser pensado como o "estranho" de que fala Freud, numa antecipação do que a estética de hoje vê na arte contemporânea.

Kristeva, sobre o abjeto, afirma: "não é a repulsa física o que causa o abjeto, falta de limpeza, de saúde, mas a perturbação da nossa identidade, do sistema, da ordem" (Kristeva, 1986, p. 4). O abjeto é o estranho. Ao nos depararmos com o abjeto, pelo fato dele nos pertencer, nos aproximamos dele e ao mesmo tempo nos afastamos. É o reconhecimento do indivíduo no abjeto que causa a repulsa e atração, emergindo o estranhamento.

É importante observar que a apreciação da pintura de Bacon exige uma concepção estética que reconheça na obra de arte uma realidade ontológica, isto é, que são seus próprios elementos constitutivos que, numa tensão interna, são capazes de provocar efeitos ou, para usar as suas 
palavras, as sensações que são o seu objetivo último. A obra é o sujeito de seus efeitos, a arte pensa, de modo que esses efeitos têm origem na própria obra e não na mente do artista ou do receptor.

Referindo-se a Van Gogh, Bacon afirma que seus quadros não mostram girassóis, mas sensações advindas das forças invisíveis de sua germinação. Este é o fio que liga o seu trabalho também ao de Picasso, Paul Klee e de Cézanne, que consideravam que a pintura deveria "tornar visíveis forças invisíveis" (Borges, 2010).

A mesmice, os clichês, a homogeneização, frutos do silenciamento do sujeito, são testemunhos do que Freud (1920/2006e) apontou como efeitos do "para-além do princípio do prazer", lugar do gozo não limitado pelo princípio homeostático do retorno à menor tensão, fruto da aludida conjunção entre capitalismo e ciência moderna. Psicanálise e arte se aproximam em seus efeitos de profanação, inclusive e, sobretudo, dessa conjunção.

\section{Considerações Finais}

Para a psicanálise, o sujeito é também o sujeito do pensamento - pensamento inconsciente. Trata-se, então, não do sujeito cartesiano, e nem mesmo de um sujeito da "desrazão", como se poderia supor. O sujeito do inconsciente, e suas manifestações no sonho, no sintoma etc., tem a sua lógica, que é apreendida através do método psicanalítico.

Se, para Descartes, o sujeito está para o pensamento, para Lacan, o sujeito também o está, mas, enquanto barrado, apagado. Em lugar do "Penso, logo sou", está o "penso, ali onde não sou". O sujeito da psicanálise é efeito da articulação significante, articulação sempre referida ao desejo. E lá onde se encontra o desejo, está o sujeito. Sujeito que pode emergir pelo método da associação livre, embora nenhum significante possa defini-lo - nem definir seu desejo, que corre metonimicamente de um objeto a outro. Sustentar a existência desse saber inconsciente sobre o desejo é o dever ético que a psicanálise propõe à civilização. Esta é a sua possibilidade de profanação dos dispositivos como mecanismo de poder homogeneizadores.

Da mesma forma, o artista pode, com a sua arte, evidenciar de maneira poética a sensibilidade e a imaginação de seu tempo. É dessa maneira que podemos descolar a prática artística de laços mais estreitos, para pensar os seus efeitos sobre a cultura. Se nos restringirmos ao século XX, surrealismo e dadaísmo foram a expressão contundente da crítica que a filosofia com Marx, Freud, Sartre, e inclusive Lacan, vinham fazendo ao seu tempo.

Entre os dadaístas e surrealistas, é possível encontrar esta crítica, que excede o campo das artes, e que as aproxima da psicanálise. Jean Arp (1886-1996), artista que participou tanto do dadaísmo quanto do surrealismo, afirma: "O renascimento inflou a razão humana de orgulho. Os tempos modernos, com sua ciência e tecnologia, fizeram do homem um megalomaníaco. A confusão atroz de nossa época é consequência dessa superestimação da razão" (Arp citado por Silvester, 2006, p. 209).

Não é difícil perceber que sob esta crítica negativa da cultura, que continua a ser a marca da arte contemporânea, pulsam as descobertas da psicanálise. Para Beuys, um dos artistas mais originais e influentes na contemporaneidade, isto significa trabalhar na direção da verdade conforme Heidegger, para quem "é somente quando o homem enquanto pastor do ser espera a verdade que ele pode esperar uma mudança no destino do ser" (Heidegger, 2008, p. 110).

\section{Referências}

Agamben, G. (2002). Homo sacer: o poder soberano e a vida nua I (H. Burigo, Trad.). Belo Horizonte: Editora UFMG.

Agamben, G. (2007). Profanações. São Paulo: Editora Boitempo.

Agamben, G. (2009). O que é o contemporâneo? e outros ensaios. Chapecó, SC: Argos.

Agamben, G. Deus não morreu. Ele tornou-se dinheiro. Entrevista com Giorgio Agamben. Instituto Humanitas Unisinos - IHU Online, 30 ago. 2012. Disponível em: <http://www.ihu.unisinos.br/noticias/512966giorgio-agamben $>$.

Agamben, G. (2014). O amigo e o que é um dispositivo. Chapecó, SC: Argos.

Bataille, G. (2006). Oeuvres complètes. Paris: Gallimard.

Borges, S. (2010). Psicanálise, linguística, linguisteria. São Paulo: Escuta.

Depelsenaire, Y. (2008). Un musée imaginaire lacanien. Paris: La lettre volée.

Freud, S. (2006a). Inibição, sintoma e angústia. (1926). In Edição Standard Brasileira das Obras Psicológicas Completas de Sigmund Freud (Vol. XX). Rio de Janeiro: Imago. (Originalmento publicado em 1926)

Freud, S. (2006b). O mal estar na cultura. In Edição Standard Brasileira das Obras Psicológicas Completas de Sigmund Freud (Vol. XXI). Rio de Janeiro: Imago. (Originalmente publicado em 1930) 
Freud, S. (2006c). Análise Terminável e Interminável. In Edição Standard Brasileira das Obras Psicológicas Completas de Sigmund Freud (Vol. XXIII). Rio de Janeiro: Imago. (Originalmente publicado em 1937)

Freud, S. (2006d). O estranho. In Edição Standard Brasileira das Obras Psicológicas Completas de Sigmund Freud (Vol. XVII). Rio de Janeiro: Imago. (Originalmente publicado em 1919)

Freud, S. (2006e). Além do princípio do prazer. In Edição Standard Brasileira das Obras Psicológicas Completas de Sigmund Freud (Vol. XVIII). Rio de Janeiro: Imago. (Originalmente publicado em 1920)

Heidegger, M. (2002). Ser e tempo (1927). Petrópolis, RJ: Vozes.

Heidegger, M. (2008). Carta sobre o humanismo. In Marcas do Caminho. Petrópolis, RJ: Vozes.

Kristeva, J. (1986). Powers of horror: an essay in abjection. Nova York: Columbia Press.

Lacan, J. (Inédito). O Seminário, livro 6: O desejo e sua interpretação (1959-1960).

Lacan, J. (1992a). O Seminário, livro 3: As psicoses (19551956). Rio de Janeiro: Jorge Zahar.

Lacan, J. (1992b). O Seminário, livro 17: O avesso da psicanálise (1969-1970). Rio de Janeiro: Jorge Zahar.

Lacan, J. (1998a). Joyce, o Sintoma (1975). In Outros escritos. Rio de Janeiro: Jorge Zahar.

Lacan, J. (1998b). Observação sobre o relatório de Daniel Lagache: Psicanálise e estrutura da personalidade (1961). In Escritos. Rio de Janeiro: Jorge Zahar.

Lacan, J. (2005). O Seminário, livro 10: A angústia (19621963). Rio de Janeiro: Jorge Zahar.

Pommier, G. (1990). O desenlace de uma análise. Rio de Janeiro: Jorge Zahar.

Silvester, D. (2006). Sobre arte moderna. Rio de Janeiro: CossacNaif.

Soler, C. (2012). Declinações da angústia. São Paulo: Escuta.

Žižek, S. (1992). Eles não sabem o que fazem. O sublime objeto da ideologia. Rio de Janeiro: Jorge Zahar.
Endereço para correspondência:

Sonia Borges

Endereço: Rua Alberto de Campos, ${ }^{\circ}$ 166, apto. 401, Ipanema. Rio de Janeiro/RJ. CEP: 22411-030.

E-mail: sxaborges@gmail.com 